\title{
A Libéria e a construção do nexo entre segurança e desenvolvimento ${ }^{1}$
}

Liberia and the construction of the security/development nexus

PAULO ESTEVES*

LETÍCIA CARVALHO DE SOUZA**

Rev. Bras. Polít. Int. 54 (2): 22-45 [2011]

\section{Introdução}

Os debates acerca das formas de produção da aquiescência de Estados nacionais às normas internacionais de direitos humanos, ou a querela em torno do problema da intervenção humanitária, são efeitos das transformações no sistema internacional que tiveram lugar após a Guerra Fria. Na medida em que aumentaram as demandas colocadas sobre a ONU em relação à manutenção da ordem por meio da expansão de regimes democráticos, as questōes relacionadas aos limites de uma ordem internacional assentada sobre o princípio da soberania ganharam centralidade. De fato, o vínculo causal entre democracia e segurança, que então se estabeleceu, deu azo a uma agenda política normalizadora; uma agenda que supõe que a segurança internacional não é resultado da balança de poder, senão da difusão de regimes democráticos (normais) - por princípio avessos à guerra ${ }^{2}$. Ao final da década de 1990, a democracia já é tomada como condição que autoriza o predicamento da soberania. O novo vocabulário posto em circulação a partir de Uma Agenda para a Paz não representa uma realidade previamente constituída. Ao contrário, é com esse novo vocabulário que são estabelecidas novas relações de poder orientadas pela transformação de sociedades nacionais a partir de um modelo liberal democrático. "Segurança humana" e "responsabilidade de proteger" tornaram-se, assim, apenas alguns dos conceitos que compõem o vocabulário

1 Este artigo foi produzido a partir do resultado de pesquisas cuja realização deveu-se ao generoso financiamento do Conselho Nacional de Desenvolvimento Científico e Tecnológico (CNPq).

* Professor do Instituto de Relações Internacionais (IRI) da Pontifícia Universidade Católica do Rio de Janeiro (PUC-Rio) (esteves.pauloluiz@gmail.com).

** Doutoranda em Relações Internacionais pelo IRI-PUC-Rio (leticiacarvalhos@yahoo.com.br).

$2 \mathrm{O}$ tema da "paz democrática" e sua relação com a transformação das operações de manutenção da paz foi tratado em Esteves e Souza (2008). Acerca dos debates em torno desse tema, veja-se, por exemplo, Russett e Maoz (1993), Doyle (1996), Owen (1996); Buchanan e Keohane (2004), Reus-Smit (2005) e Doyle e Macedo (2008). 
normalizador, apontando para a convergência entre as agendas de desenvolvimento e segurança internacional ${ }^{3}$. Cabe, contudo, indagar: como em um sistema orientado pelo princípio da soberania, e por seu corolário de não intervenção, tais conceitos puderam emergir? Como esse vocabulário foi capaz de informar um conjunto de práticas nos campos da segurança internacional, particularmente as Operações de Manutenção da Paz (OMP)? Esse artigo pretende identificar algumas das práticas de normalização que emergiram com o fim da Guerra Fria no interior das OMP. A hipótese de trabalho proposta afirma que (i) as transformações sofridas pelas OMP refletem uma redefinição do que significa a paz e dos meios pelos quais ela deve ser alcançada, principalmente no que concerne à transformação dos regimes políticos domésticos; e (ii) tais transformaçōes assinalam a convergência entre as práticas de desenvolvimento e de segurança no interior das práticas das OMP. Nesse sentido, pretende-se reunir evidências que permitam discutir como se processa o nexo entre segurança coletiva e assistência ao desenvolvimento por meio do estudo do caso da Libéria, usualmente considerado exemplar pelos operadores da própria ONU. O artigo propõe um recorte temporal que compreende os anos de 2003 a 2008 - coincidentes com o desdobramento da United Nations Mission in Liberia (Unmil). Tal recorte permite identificar alguns dos principais lineamentos das transformações institucionais que permitiram a criação e o desdobramento das chamadas OMP multidimensionais, portadoras de mandatos que compreendem aspectos relacionados às praticas de segurança e desenvolvimento.

$\mathrm{O}$ artigo encontra-se organizado em torno de quatro seçóes. Inicialmente, apresentamos uma revisão acerca das transformações das OMP após a Guerra Fria, tomando como objeto primário a documentação produzida no interior do sistema ONU. A segunda e terceira seçôes tratam do caso liberiano. Embora o estudo de caso compreenda apenas o período de 2003 a 2008, a segunda seção trata de forma sumária os eventos que conduziram à crise humanitária que eclodiu após a posse do presidente Charles Taylor. A terceira seção apresenta, então, o estudo de caso, e por meio da análise dos mandatos e orçamentos da Unmil reúne evidências da convergência entre as práticas de segurança e desenvolvimento na Libéria. Finalmente, a quarta e última seção oferece algumas considerações finais acerca das transformaçōes das OMP à luz das evidências recolhidas do caso liberiano.

\section{Operações de manutenção da paz após a Guerra Fria}

Este artigo não pretende fazer uma revisão exaustiva da literatura que trata das transformaçōes recentes das OMP. Ao contrário, por meio do recurso a documentos produzidos no interior do sistema ONU e do apoio na assim chamada bibliografia critica, o objetivo desta seção é apenas apontar o vínculo entre as transformações dos

3 A esse respeito, veja-se Esteves (2010a). 
entendimentos intersubjetivos acerca do que é a paz e de como deve ser alcançada, de um lado, e as transformações das OMP, de outro. Nesse sentido, optamos por não tratar a vasta bibliografia orientada por uma perspectiva que Pugh (2004) e Bellamy e Williams (2004) nomearam "solução de problemas" (problem solving), a bem do que esses autores chamaram de abordagens criticas ${ }^{4}$. Nesta seção buscaremos acompanhar o processo de transformação das OMP até a emergência das operações multidimensionais, enfatizando os vínculos conceituais que se estabelecem entre os campos da segurança internacional e do desenvolvimento.

A criação da ONU teve lugar em um contexto de reconstituição do sistema internacional de segurança coletiva; tentava-se, então, devolver a estabilidade às relações entre os Estados como reação ao legado de profunda instabilidade deixado pela Segunda Guerra Mundial. Em meio a esse esforço, a concepção wilsoniana de paz, universal e indivisível, foi reescrita como limitação e proscrição do uso da força por meio da classificação do ato de agressão como uma espécie de "ilícito internacional”, ao qual todos os demais Estados estariam compelidos a responder de forma conjunta (Claude 1956). Entretanto, o fim da Guerra marcou também a emergência de duas superpotências e de uma ordem internacional marcada pela bipolaridade e deterrência, que oferecia escassas possibilidades de mobilização dos mecanismos multilaterais de produção de aquiescência (Gaddis 2005). Ainda assim, alguns elementos do sistema de segurança coletiva foram preservados, com o endosso das potências, na construção da nova ordem, com destaque para limitação do uso da força e da contenção de eventuais escaladas ou transbordamentos dos conflitos internacionais. Esta última, reforçada pelo temor de que o envolvimento de norte-americanos e soviéticos em disputas regionais pudesse precipitar uma nova guerra mundial.

De fato, entre seus inúmeros efeitos, a divisão do mundo impingiu às potências grande parte das responsabilidades e dos custos envolvidos na operação do sistema de segurança coletiva, cada uma em seu bloco. Com isso, o recurso a mecanismos multilaterais para combater ameaças à paz, como os oferecidos pela ONU, foi bastante esvaziado, e, em geral, reservado a casos que não envolviam os interesses imediatos das grandes potências ou produziam ameaças de conflitos entre elas. As OMP foram a fórmula clássica encontrada para lidar com esses casos,

\footnotetext{
4 Pugh (2004) e Bellamy (2004) identificam duas tendências no tratamento do problema das OMP pela literatura do campo das relaçôes internacionais: "problem solving" e autores críticos. No primeiro grupo encontramos abordagens que se concentram em torno de uma perspectiva marcada pelo debate acerca dos recursos disponíveis para as operações em face de seus mandatos, ou do compromisso dos Estados em relação às necessidades do campo. Assim, sua ênfase recai sobre aspectos relacionados à sua efetividade, eficácia e eficiência das OMP, a partir do ponto de vista da resolução de problemas (problem solving). Sob essa perspectiva, veja-se, por exemplo, Lewis e Julian (1992), Durch (1993), Durch et al. (2003) e Lederach (2003, 2002). As abordagens criticas, por seu turno, enfatizam o relacionamento entre as transformaçōes em curso no sistema internacional e as práticas das OMP. Nesse segundo grupo, encontram-se, entre outros, Paris (2001), Pugh (2004), Bellamy e Williams (2004), Richmond (2005), Richmond e Franks (2009), Richmond (2010), Chandler (2002, 2004) e Duffield (1994, 2001).
} 
e se mantiveram consistentes com o objetivo de limitar o uso da força e estabilizar as situações de crise, principalmente por meio da separação entre beligerantes e restituição da autoridade soberana nas áreas afetadas.

O final da Guerra Fria inaugurou um período de grandes transformaçōes no sistema internacional. Por um lado, cresceu o número de conflitos violentos e guerras civis; por outro, o aumento da interdependência entre os Estados sinalizava o fortalecimento do multilateralismo e o maior engajamento das organizaçóes multilaterais nos assuntos internacionais. Tal ambiente foi ocasião para o avanço de um conjunto de princípios de cunho liberal que afirmava a primazia dos direitos individuais e apontava para a possibilidade de que tais direitos fossem realizados e garantidos internacionalmente. Nesse contexto, teve lugar a elaboração de Uma Agenda Para a Paz, relatório encaminhado pelo então Secretário-Geral BoutrosGhali ao Conselho de Segurança, em 1992. No documento, o Secretário-Geral afirmava que o fim do antagonismo entre as potências daria uma nova oportunidade para a ONU; entretanto, para que pudesse aproveitá-la, a organização teria que contar com o compromisso de seus membros e enfrentar novos desafios. Para tanto, a Agenda propunha o fortalecimento das práticas de segurança coletiva, revisitando os conceitos de diplomacia preventiva, peacemaking e peacekeeping (OMP) e acrescentando um novo instrumento: o peacebuilding pós-conflito.

De acordo com a Agenda, cada um dos instrumentos desempenharia um papel específico na manutenção da segurança internacional e relacionar-se-ia a um dos novos objetivos da atuação da ONU, que seriam: (i) identificar e neutralizar situaçóes potencialmente conflituosas, por meio da diplomacia preventiva, antes que resultem em violência; (ii) se iniciado o conflito, engajar-se em interrompê-lo e buscar soluções para suas causas, via peacemaking; (iii) com o peacekeeping, trabalhar para preservar a paz e assistir a implementação de acordos onde as batalhas tiverem sido suspensas; e (iv) assistir à reconstrução das instituições e da infraestrutura dos Estados afetados pela guerra, por meio do peacebuilding pós-conflito (ONU 1992)5.

A Agenda oferecia um novo entendimento acerca das OMP, enfatizando atividades de reconstrução, especialmente em casos de conflitos intraestatais e guerras civis: "[...] somente um trabalho sustentado e cooperativo que trate os problemas econômicos, sociais, culturais e humanitários que subjazem aos conflitos pode garantir uma fundação durável à paz alcançada" (ONU 1992, \$57)

Como resultado, as OMP foram reinterpretadas como um primeiro estágio do processo de reconstrução e pacificação, no qual a deposição das armas abriria caminho para o "[...] suporte à transformação de estruturas e capabilities nacionais deficientes e para o fortalecimento de novas instituiçōes democráticas” (ONU 1992, \$59), descrito na Agenda como uma obrigação.

5 Para interpretações criticas acerca de Uma Agenda para Paz, veja-se Debrix (1999) e Chandler (2002).

6 A tradução desta e de outras citações foi realizada pelos autores. 
A articulação dessas propostas parece ter ocorrido em torno do conceito de segurança humana, definido pela primeira vez no Relatório de Desenvolvimento Humano, publicado pelo Programa das Nações Unidas para o Desenvolvimento (PNUD) em 1994. Segundo o documento, a "segurança humana abrange a proteção contra ameaças crônicas, como fome, doenças e repressão, e também contra o rompimento dos padrões da vida cotidiana" (apud CGG 1996, 59) e desdobrar-se-ia em sete áreas: segurança econômica, alimentar, pessoal, comunitária, política, de saúde e do meio ambiente (PNUD, 1994).

O sucesso inicial do conceito foi reforçado pela publicação, ainda em 1994, de uma série de estudos do Banco Mundial, intitulada Voices of the Poor. Os resultados indicavam a segurança como a primeira preocupação entre os mais carentes, deixando para trás necessidades básicas, como abrigo e comida (Chandler 2007), o que levou a equipe do Banco Mundial a classificá-la como condição de possibilidade para a melhoria das condições de vida das populações mais pobres, especialmente as diretamente afetadas por conflitos. Entretanto, naquele contexto, a segurança não poderia restringir-se à observância de interesses estratégicos, tal como no passado; o conceito teria de ser alargado para incluir elementos da ordem interna relacionados à melhoria das condições de vida.

Conforme a definição da ONU, a

segurança humana, em sua forma mais ampla, engloba muito mais que a ausência de conflitos violentos. Inclui direitos humanos, boa governança, acesso à educação e à saúde e garantia de que cada indivíduo tenha oportunidades e escolhas que proporcionem a realização de todo o seu potencial. Cada passo nessa direção é também um passo rumo à redução da pobreza, ao crescimento econômico e à prevenção de conflitos. (CSH 2003, 4).

O conceito de segurança humana produzia, então, o vínculo entre a agenda de segurança coletiva e as práticas de assistência ao desenvolvimento. Tal vínculo deu azo à noção, enunciada no relatório final da Carnegie Commission on Preventing Deadly Conflict (1997), de que o sucesso da prevenção de conflitos pelo tratamento de suas causas profundas (estruturais) dependeria da capacidade dos atores internacionais de induzir e coordenar processos de transformação social, baseados na consolidação de estruturas de proteção dos direitos fundamentais, instituições democráticas e políticas de desenvolvimento. Com isso, a segurança humana se firmava como um conceito capaz de informar a reestruturação de todo o leque de políticas de combate às ameaças à paz e à segurança internacionais da ONU.

A apropriação do conceito logrou especial sucesso no campo das operaçôes de paz, servindo de base para a emergência de debates em torno do problema da intervenção humanitária, bem como para a enorme diversificação das atividades 
incluídas nos mandatos das missões a partir dos anos 1990. Em meio a esse processo, as OMP tradicionais acabaram por dar lugar às operações multidimensionais, mais ambiciosas e intrusivas, lançadas “[...] com o objetivo de auxiliar a reconstrução das bases políticas, econômicas e sociais dos países em vias de sair de processos de guerras civis" (Paris 2007, 405) e, assim, "[...] aliviar o sofrimento humano, criar condiçôes e construir instituiçôes para a paz auto-sustentável” (DPKO 2007). De acordo com o Departamento de Operaçóes de Paz - Department of Peacekeeping Operations (DPKO) -, as principais atribuições das missões conduzidas pela ONU passaram a ser: (i) prevenir a eclosão do conflito ou sua difusão além-fronteiras; (ii) estabilizar situações conflituosas depois do cessarfogo e criar um ambiente favorável a acordos de paz duradouros; (iii) assistir a implementação desses acordos; e (iv) guiar Estados ou territórios na transição para governos estáveis, baseados em princípios democráticos, boa governança e desenvolvimento econômico (DPKO 2007).

As novas operações de paz, portanto, "[...] envolvem o uso da força como parte de um esforço mais amplo para promover reformas políticas e econômicas com objetivo de transformar aquelas sociedades saindo de conflitos em sociedades em paz consigo mesmas e com seus vizinhos" (Dobbins et al. 2007, XVII). Dessa forma, em consonância com os conceitos de segurança humana e prevenção, a implementação de políticas de desenvolvimento e a construção de instituições democráticas foram colocadas como parte fundamental do processo de pacificação das sociedades sujeitas a intervenções internacionais.

É importante ressaltar que, por mais que as propostas de reformulação das operaçôes de paz retomadas aqui façam referência a noçóes como direitos individuais e ressaltem o papel da sociedade internacional na pacificação das regióes em conflito, a garantia da segurança em longo prazo continuaria a passar pela construção - ou reconstrução - de arranjos estatais. Mesmo nas formulações mais universalistas, a defesa dos direitos básicos dos indivíduos cabe fundamentalmente a Estados particulares, e só deve ser assumida pela sociedade internacional quando estes mostrarem-se incapazes de garanti-la. Assim, a ONU reconhece os Estados soberanos como entidades fundamentais da comunidade internacional; paralelamente, sugere que o exercício das prerrogativas decorrentes de sua forma soberana deve estar cada vez mais atrelado a um conteúdo específico, composto de práticas de boa governança ${ }^{7}$.

O reforço da importância dos Estados para a manutenção da paz e a necessidade de reformar muitos deles para que pudessem dar conta de tal tarefa fizeram com que as doutrinas de operações de paz incluíssem, de forma marcante, orientações para a reconstrução da estrutura estatal em todos os seus aspectos, o que

7 A esse respeito veja-se, por exemplo, Richmond (2004, 2008). 
está na base da ideia de multidimensionalidade ${ }^{8}$. Mais do que isso, o desdobramento dessas operações passou a prever a participação de um número crescente de agências governamentais e da própria ONU, além de atores não estatais, como ONGs, e a atribuir a eles papéis mais relevantes. Nesse sentido, Paris (2007) afirma que as operações de paz teriam ressurgido a partir dos anos 1990 como uma

[...] rede vasta, complexa e crescente de agências privadas e públicas que fornecem um tipo de "suporte à vida" a estados frágeis emergindo de conflitos - um sistema descentralizado (e algumas vezes caótico) para reestruturar a sociedade civil pacífica, a governança efetiva e a vida econômica nos estados tomados pela guerra. (Paris 2007, 410).

Para dar conta da multiplicidade e da complexidade das tarefas e do número de atores envolvidos em sua realização, essas operações passaram por ampla reformulação operacional, com redefinição das regras de engajamento e de elaboração dos mandatos, consolidação de processos de captação e utilização de recursos, integração dos projetos realizados, reforço dos mecanismos de coordenação entre atores, e reformulação das orientações táticas e estratégicas para as equipes no campo. Tais transformaçóes foram reunidas e sistematizadas pelo DPKO na Doutrina Capstone (DPKO 2008), que divide o processo de paz em três grandes fases - estabilização, consolidação da paz, e recuperação e desenvolvimento em longo prazo -, sendo cada uma delas caracterizada por um conjunto específico de tarefas e de atores.

Nesse cenário, a Libéria aparece como "laboratório" no qual é possível identificar a reestruturação dos instrumentos de segurança coletiva e o progressivo vínculo entre segurança e desenvolvimento. As duas próximas seções pretendem identificar os principais lineamentos de tais transformaçôes. De forma geral, interessa mostrar como narrativas históricas sobre a Libéria - e os diagnósticos por elas apresentados acerca das causas de seus sucessivos conflitos - refletem a consolidação desse vínculo entre segurança e desenvolvimento, e, ainda, como este informa as estratégias elaboradas pela ONU e seus principais parceiros para lidar com a situação.

8 O conceito de multidimensionalidade foi proposto a partir de Uma Agenda para Paz e aponta para uma compreensão de que a paz é resultado da transformação de conflitos por meio da "expansão das capacidades (reconstrução econômica) e transformação institucional (reforma das forças policiais, do sistema judiciário, do aparato de defesa, promoção de eleições e reconstrução da sociedade civil) (Doyle 2006, 15). A emergência das OMP multidimensionais é, usualmente, relacionada à sucessão de "gerações" de OMP que, por sua vez, estariam referidas às transformações da própria natureza dos conflitos. A análise das transformaçôes das OMP com base na ideia de "gerações" é aqui rejeitada por duas razões. Em primeiro lugar, porque sugere uma perspectiva evolucionista. Em segundo lugar, porque relaciona as transformaçôes das OMP à transformação dos conflitos, tratados, por exemplo, sob o conceito de novas guerras. O presente artigo, em outra direção, relaciona a transformação das $\mathrm{OMP}$ às transformaçôes da própria ordem internacional e à emergência de um novo entendimento intersubjetivo acerca da paz e das formas de alcançá-la. A respeito da abordagem geracional das OMP veja-se Durch (1993, 2006) e Doyle e Sambanis (2006). Para uma crítica à perspectiva geracional, veja-se Duffield (1994, 2001) e Esteves (2010a, 2010b). 


\section{A guerra civil liberiana e o desdobramento da United Nations Observer Mission in Liberia (Unomil)}

A Libéria ganhou notoriedade por ter sido o primeiro Estado africano a declarar independência, em 1847, sem ter vivido intensa dominação colonial. Apesar disso, sua história é marcada por grande instabilidade política e profunda ligação com o exterior, especialmente com os Estados Unidos (Morgan 2006). Embora descoberta por portugueses no século 15, a região foi intensamente disputada por corsários britânicos e holandeses, que procuraram estabelecer entrepostos comerciais devotados ao comércio de escravos (David 1984; Sawyer 2004). Em 1821, a região foi adquirida pela American Colonization Society (ACS)9, uma organização fundada nos Estados Unidos, em 1816, com objetivo de enviar de volta à África os escravos que, segundo eles, não teriam mais lugar na sociedade norte-americana; expandir as relaçôes comerciais dos EUA com a África; e civilizar a população nativa (Aning 1999; Wickstrom 1960; David 1984). No ano seguinte, aportaram os primeiros colonos, que estabeleceram assentamentos ao longo da costa e acabaram por fundar uma espécie de commonwealth (Nelson 1984) ${ }^{10}$.

Como observam Aning (1999) e Sayle et al. (2009), desde sua criação, a Libéria contou com um aparato administrativo semelhante ao colonial, no qual a ACS exercia o papel de autoridade política, organizando a produção, o comércio e as relações sociais. Sobre esse último aspecto, Nelson (1984) e Levitt (2005) destacam a submissão imposta pelos imigrantes vindos dos EUA aos nativos, classificados como "aborígenes não civilizados" (Nelson 1984, XXIV), que teve início no período de administração branca (1822-1842), foi legalizada na Constituição de 1847 - posterior à independência -, e perdurou, pelo menos, até os anos 1980, ainda que não mais constitucionalmente. Mesmo depois da independência, os laços entre a Libéria e os EUA continuaram fortes, com a promulgação de uma constituição de inspiração norte-americana e a ascensão ao poder de um presidente negro nascido na Virgínia. Além disso, grande parte das atividades produtivas do país era financiada por empresas ou pelo governo dos EUA, que também concedia empréstimos frequentes ao governo local (Aning 1999).

Se comparada à maior parte dos Estados africanos, é possível afirmar que, após a independência, a Libéria passou a desfrutar de uma posição política relativamente tranquila no cenário internacional (Sayle et al. 2009). Paralelamente, sua política interna era marcada pela fragilidade estrutural e institucional e pela inabilidade de seus líderes na mediação de relações sociais eivadas de tensões, especialmente com as tribos nativas (Aning 1999). Em 1980, essa tensão culminou com a deposição e execução do então presidente William Tolbert Jr. a mando do sargento Samuel Doe, líder do Conselho de Redenção Popular - People's Redemption Council

9 Sobre a ACS, ver Purvis (1997).

10 Sobre sociedades colonizadoras e assentamentos na costa da Libéria, ver Aning (1999). 
(PRC) -, eleito presidente em 1985, em um pleito que excluiu a oposição (Adebajo 2002). Durante os anos de seu governo, Doe fomentou rivalidades internas e disputas étnicas, além de ter se beneficiado de maneira ilícita dos recursos naturais explorados na Libéria (Harris 1999). Mesmo assim, o presidente contou com o apoio dos EUA, que, interessados em manter um aliado contra os soviéticos na África, destinaram à Libéria mais de US\$ 500 milhões entre 1980 e 1989 (Howe 2001). Em 1989, grupos guerrilheiros - a maioria compostos por integrantes de minorias étnicas perseguidas por Doe - liderados pela National Patriotic Front of Liberia (NPFL) se rebelaram contra as forças do governo, dando início à guerra civil (Adebajo 2002).

De acordo com dados da ONU, o conflito deixou mais de 200 mil mortos - inclusive o presidente - e desalojou cerca de $80 \%$ da população do país, entre deslocados internos e refugiados, o que teria contribuído para o agravamento da já precária situação dos Estados vizinhos, especialmente Serra Leoa e Costa do Marfim (UNDAF 2003). A primeira tentativa internacional de intervir na Libéria foi liderada pela Comunidade Econômica dos Estados da África Ocidental - Economic Community Of West African States (Ecowas) -, com o envio de uma força de paz em 1990, a Ecowas Cease-fire Monitoring Group (Ecomog), que contou com o apoio da ONU e da Organização da Unidade Africana (Aning 1999). Em 1992, o Conselho de Segurança determinou o embargo geral e completo de todas as entregas de armas e equipamentos militares à Libéria (S/RES/788).

Entretanto, mesmo depois do embargo, a participação da ONU se manteve indireta por um período de quase um ano. Somente quando a Ecowas conseguiu negociar o cessar-fogo entre as partes (Acordo de Paz de Cotonou, de 1993), o Conselho determinou a criação de uma OMP na região, a United Nations Observer Mission in Liberia (Unomil), a primeira na história da ONU a ser realizada em conjunto com uma operação preexistente conduzida por outra organização - nesse caso a Ecowas (S/RES/866 1993).

De acordo com a resolução do Conselho, a Unomil tinha como atribuições principais:

monitorar o cumprimento [...] do Acordo de Paz [...] e verificar sua aplicação imparcial; assistir o monitoramento do cumprimento do embargo ao fornecimento de armas e equipamentos militares à Libéria e o alojamento, desarmamento e desmobilização dos combatentes; observar e verificar o processo eleitoral [...]; assistir a coordenação das atividades de assistência humanitária no campo [...]; planejar e angariar recursos para a desmobilização de combatentes; comunicar qualquer violação grave do direito humanitário internacional [...]; coordenar, em conjunto com a Ecomog, a identificação de minas e bombas e assistir seu desarmamento. (S/RES/866 1993, \$ 3).

Em 1995, após o reaparecimento de focos de tensão, o mandato da Unomil foi ajustado - ainda que não de forma significativa -, dando à missão papel mais ativo na implementação de acordos e programas e suporte às atividades de assistência 
humanitária e aos grupos de direitos humanos, além da recomendação de medidas para prevenir a retomada do conflito (S/RES/1020 1995). Com a realização de eleições e o estabelecimento de um novo governo em 1997, a ONU considerou que a tarefa da missão havia sido cumprida e encerrou suas atividades em 30 de setembro daquele ano. Ainda em 1997, o Conselho determinou a criação da United Nations Peace-building Support Office in Liberia (Unol), que deveria, junto com o governo, facilitar a promoção de reconciliação nacional e boa governança (UN 2000). A Unol foi a primeira experiência de organização de suporte à reconstrução pós-conflito criada pela ONU; contudo, suas atividades foram posteriores à OMP na região, e não parte dela ${ }^{11}$.

\section{O desdobramento da Unmil}

Com a posse do presidente Charles Taylor e o encerramento da missão, as tensões voltaram a emergir na Libéria. Grupos rebeldes e milícias passaram a contestar a autoridade do governo e assumiram o controle sobre algumas regióes do país, dando início à escalada de violência, abusos sistemáticos dos direitos humanos, perseguições e criminalidade generalizada, praticados não só pelos milicianos como também pelo governo (Sawyer 2004). Entre os rebeldes, destacaram-se o Liberians United for Reconciliation and Democracy (Lurd), que estabeleceu domínio paralelo no norte; e o Movement for Democracy in Liberia (Model), cuja preponderância crescia no sul (Sayle et al. 2009). Esses grupos foram apoiados pelos países vizinhos - Guiné e Serra Leoa -, que mantinham relações conflituosas com a Libéria, principalmente em decorrência do apoio do presidente Taylor a milícias contrárias aos governos desses países (ICG 2003) ${ }^{12}$. A precariedade das condições de vida na Libéria fortalecia as milícias, fazendo com que, já em 2003, apenas um terço do território permanecesse controlado pelo governo (Sayle et al. 2009; Hoffman 2006). Em pouco tempo, o acesso ao sul foi bloqueado pelo Model, enquanto o Lurd cercava a capital Monróvia (S/2003/875 2003).

Diante do agravamento do conflito e da proposta da Ecowas, apoiada pelos EUA, de enviar tropas para região, o então Secretário-Geral Kofi Annan remeteu uma carta ao Conselho de Segurança na qual sugeria a realização de intervenção internacional na Libéria, a ser desdobrada em três fases: (i) envio de tropas da Ecowas; (ii) envio de força multinacional; e (iii) estabelecimento de OMP da ONU (S/2003/769 2003). Em resposta, o Conselho autorizou o envio imediato dos contingentes, ancorando sua ação no Capítulo VII da Carta da ONU, visando à criação de condições para o estabelecimento de uma OMP, a qual deveria ser delineada pelo Secretário-Geral o mais rápido possível (S/RES/1497 2003). Paralelamente ao envio das tropas, a ONU passou a negociar o acesso livre e

11 As atividades da Unol foram encerradas em 2003, quando, em decorrência da retomada dos conflitos, a ONU estabeleceu uma nova operação de paz na Libéria, a Unmil, cujas atividades serão descritas e discutidas em seguida.

12 Sobre o tema, ver Ndumbe e Babalola (2005). 
seguro dos atores humanitários à população (S/2003/875 2003). Com o acordo de paz (Accra Comprehensive Peace Agreement) e o estabelecimento do governo provisório, o Secretário-Geral elaborou novo relatório, no qual recomendava a criação imediata da OMP e delineava seus termos (S/2003/875 2003). Acatadas as sugestōes, o Conselho de Segurança determinou a instituição da Unmil, ainda em 2003, com mandato de 12 meses (S/RES/1497 2003) ${ }^{13}$.

Conforme descrito pela ONU, a partir de 2003, o caso da Libéria demonstra claramente como a deterioração das condições humanitárias e a continuidade dos conflitos internos podem ultrapassar fronteiras nacionais e impingir riscos ao sistema internacional como um todo. Mais do que isso, o diagnóstico e o corolário de medidas proposto pela Organização vai ao encontro das ideias de que (i) a manutenção da paz e da estabilidade dependem da habilidade de combinar o combate às ameaças no presente à sua prevenção no futuro; e (ii) que isso seria viabilizado por uma abordagem multidimensional voltada, principalmente, para a reforma das instituiçóes e da infraestrutura estatal e para a realização de programas de desenvolvimento econômico e social, responsáveis por minar as causas mais profundas das disputas violentas.

Nesse sentido, o Conselho reconheceu uma relação entre a degeneração das condições humanitárias e a intensificação do conflito e afirmou que a situação "[...] constitui ameaça à paz e à segurança internacionais, à estabilidade na sub-região da África Ocidental, e ao processo de paz na Libéria" (S/RES/1497 2003, 1). Tal situação seria agravada, principalmente, pelo "[...] deslocamento generalizado da população, pobreza, alto índice de desemprego e proliferação de armas leves [...]" (S/2003/875 2003, \$ 23), falência das instituições, corrupção generalizada, falta de confiança no Estado, infraestrutura deteriorada, tensão permanente entre grupos sociais - incluindo disputas territoriais e elementos criminais -, violação e abusos generalizados dos direitos humanos e do direito humanitário internacional e militarização e fragmentação da sociedade civil (S/2003/875 2003). Finalmente, o Secretário-Geral concluiu que o equacionamento dessas questôes "[...] requer uma resposta abrangente, multidimensional e sustentada da comunidade internacional" (S/2003/875 2003, $\$ 116)$, por meio de açōes coordenadas entre a OMP e as mais diversas organizaçôes envolvidas em atividades para atenuar os efeitos do conflito na Libéria e evitar sua recorrência no futuro (S/2003/875 2003).

A coordenação entre diversos atores e a multidimensionalidade da abordagem sustentavam todo o leque de medidas recomendadas pelo Secretário-Geral e apropriadas pelo Conselho. Sobre esse aspecto, é interessante notar que as recomendaçóes basearam-se em estudos encomendados pelo próprio SecretárioGeral, que detalhavam as condições que a OMP encontraria na Libéria; definiam prioridades relacionadas à manutenção da paz e da estabilidade; e delineavam planos e cronogramas de ação (S/2003/875 2003). Compunham as equipes

13 As atividades foram iniciadas em seguida e, após sucessivas prorrogações do mandato, seu encerramento está previsto para setembro de 2012 (S/RES/2008 2011). 
responsáveis pelos estudos funcionários das mais diversas agências da ONU e OIs - com destaque para o Banco Mundial (S/2003/875 2003). As propostas das ONGs vinculadas à assistência humanitária também foram contempladas, mediante inclusão nas propostas do CAP/CHAP de documento elaborado por elas - em parceria com agências da ONU e doadores - que continha a lista de projetos a serem desenvolvidos em “setores vitais" (S/2003/875 2003, \$ 40).

De acordo com as recomendaçóes incorporadas ao mandato, a grande prioridade da Unmil seria estabilizar a situação de segurança e oferecer suporte às organizações humanitárias ali presentes. Mais especificamente, a instituição da missão deveria garantir o acesso dessas organizações à população local, criando condições para a ampliação da ajuda e para o estabelecimento, na região, das principais agências da ONU relacionadas à assistência humanitária, permitindo a plena realização dos projetos propostos de forma conjunta no CAP/CHAP de 2003 (e dos anos seguintes) para a Libéria (S/2003/875 2003).

Em seguida, caberia à Unmil dar início à reconstrução das instituiçóes e da infraestrutura do Estado, com destaque para o setor de segurança, e conduzir o processo eleitoral, tarefas que seriam realizadas ora em conjunto com o governo provisório, ora assumindo funçôes de Estado (S/RES/1509 2003).

Finalmente, o texto do Conselho reconheceu que, para que a paz e a estabilidade alcançadas se perpetuassem, seria necessário considerar como a comunidade internacional "[...] pode ajudar o desenvolvimento econômico futuro na Libéria, com vistas a alcançar estabilidade a longo prazo [...] e a melhorar o bem-estar de seu povo" (S/RES/1509 2003, \$15). As conclusōes sobre os caminhos da assistência ao desenvolvimento seriam apresentadas inicialmente no Common Country Assessment (CCA) e, de forma mais completa, na United Nations Development Assistance Framework (Undaf) (UNDAF Liberia 2003), que reúne os projetos de desenvolvimento a serem empreendidos no país de 2003 a 2005 e, posteriormente, de 2008 a 2012, em esforços conjuntos de agências da ONU, ONGs e OIs, com destaque para o Banco Mundial e o Fundo Monetário Internacional (FMI).

O desenrolar das atividades da Unmil, como descrito em seu mandato (S/RES/1509 2003), pode ser relido de acordo com a dinâmica do processo de paz proposta pela Doutrina Capstone (2008), e dividido em três momentos: (i) estabilização; (ii) consolidação da paz; e (iii) recuperação e desenvolvimento a longo prazo, cada um deles contando com um conjunto mais ou menos específico de atores responsáveis. Relacionada à divisão em estágios, é também possível identificar uma classificação das tarefas em três grandes áreas, que são planejadas de forma integrada e devem operar da mesma maneira: (a) segurança e reorganização institucional do Estado, detalhada no mandato e demais documentos de planejamento da OMP; (b) assistência humanitária, delineada nos documentos do CAP/CHAP ${ }^{14}$;

14 Ainda que seja definida como uma das três grandes áreas da missão, a ajuda humanitária e as propostas especificamente vinculadas a elas não serão discutidas aqui, uma vez que, por hora, o foco é a relação que se estabelece entre segurança e desenvolvimento. 
e (c) assistência ao desenvolvimento, cujo planejamento final é apresentado na Undaf. Contudo, é importante ressaltar que a divisão entre as etapas e entre as áreas não pode ser demarcada de forma precisa; pelo contrário, os limites entre elas são fluidos, com grandes zonas de sobreposição e interseção.

De qualquer maneira, é possível perceber que o planejamento e organização da Unmil incorporaram, de forma marcante, as orientaçōes normativas, institucionais e operacionais relacionadas à redefinição da própria noção de paz e dos caminhos para sua consecução. Com a inclusão da proteção humanitária e da assistência ao desenvolvimento como eixos norteadores - ao lado da segurança - e pilares da construção de uma paz e estabilidade duradouras, os oficiais da ONU consideraram que a Unmil teve êxito em colocar em prática a multidimensionalidade, o que a levou a ser inscrita entre operações de maior sucesso conduzidas pela Organização em prol da segurança coletiva (UN Forum 2005; UN Foundation 2009). Para que isso fosse possível, além da incorporação de técnicas aceitas e inovações que se provaram úteis, a operação contou com considerável apoio internacional, principalmente dos EUA, e com o engajamento de ONGs e OIs parceiras, refletidos na grande quantidade de projetos e recursos destinados à Libéria.

\section{A organização da Missão Multidimensional}

A abordagem multidimensional das OMP conduzidas pela ONU implicou, ao longo dos anos, em progressivo aumento do leque de atividades consideradas essenciais para a paz desenvolvidas nas regióes sob intervenção, bem como dos recursos e profissionais especializados considerados necessários à sua implementação. Essa demanda articulou-se a um discurso que afirmava a universalidade dos princípios que orientavam a instituição das operações e a definição de suas prioridades, como democracia e desenvolvimento, o que, no limite, funcionaria como garantia de comunhão de objetivos entre os mais diversos atores interessados em engajar-se nos processos de paz. Tal articulação abriu espaço para que as OMP passassem a incorporar grande número de novos atores e promover a divisão, entre eles, de uma parte do trabalho relacionado ao processo de paz. Entretanto, para que tal divisão fosse efetiva no campo, era necessário ampliar e aperfeiçoar os mecanismos de coordenação, tarefa que foi incluída entre as atribuiçôes do DPKO/Departamento de Apoio Logístico - Department of Field Support (DFS).

Esse processo possibilitou ao Departamento concentrar seus esforços na manutenção da segurança - definida como condição sine qua non para a realização de qualquer tarefa - e nos aspectos centrais da reconstrução do Estado, especialmente leis, instituições e infraestrutura. Ao conduzir uma operação de paz, portanto, o DPKO/DFS forjaria as bases sobre as quais a paz pudesse ser edificada, mediante trabalho coordenado de sua equipe e demais agências e organizações parceiras. Dessa forma, é possível reinterpretar o processo de reorganização das atividades - que deu azo à emergência da assistência humanitária e da assistência 
ao desenvolvimento como áreas das $\mathrm{OMP}$-, como um de divisão do trabalho relacionado à paz e à segurança, que se articulou às transformaçōes normativas, institucionais e operacionais descritas desde o epílogo da Guerra Fria.

A relação entre as três áreas pode ser descrita como de simbiose, na qual observam-se traços de integração - relacionados principalmente aos fins e ao processo de planejamento -, e de independência - garantida pela especificidade dos caminhos trilhados por cada uma delas. Conforme a Doutrina Capstone (2008), o Processo Integrado de Planejamento da Missão - Integrated Mission Planning Process (IMPP) - visa à definição de objetivos comuns entre os parceiros das OMP; porém, "esses atores têm diferentes papéis, processos de tomada de decisão, cronogramas de engajamento, procedimentos, pressões orçamentárias e autoridades de supervisão" (DPKO/DFS 2008, 55). Isso implica que, ainda que os objetivos sejam comuns, os processos são paralelos, cabendo aos coordenadores da missão "manterem-se informados sobre os demais processos de avaliação e planejamento [...] e buscarem ativamente a criação de integração substantiva entre eles, sempre que possível" (DPKO/DFS 2008, 56).

A montagem das operações de paz é bastante elucidativa em relação a esse aspecto e mostra que, apesar de serem pensadas separadamente, as atividades das três áreas são parte de um todo comum. A utilização de um caso concreto, como o da Libéria, permite acessar, de forma mais direta, as políticas desenvolvidas no campo e, com base nelas, perceber como os principais conceitos que informam as OMP são transpostos das doutrinas da ONU para o dia a dia dos profissionais que atuam no campo. Ademais, é possível notar como as tarefas compreendidas em cada uma das áreas acabam por se misturar, o que muitas vezes torna difícil reconstituir as fronteiras entre elas.

No caso da Unmil, o mandato da operação foi dividido em cinco grupos de medidas (S/RES/1509 2003), traduzidas no orçamento como cinco componentes da missão: (i) Cessar-Fogo; (ii) Direito Humanitário e Direitos Humanos; (iii) Reforma do Setor de Segurança; (iv) Processo de Paz; e (v) Suporte (A/58/539 2003). Esses componentes se mantiveram relativamente constantes durante todo o período considerado (2003-2008). As principais alterações foram realizadas em 2007, mas se limitaram à denominação do componente, sem se estender de maneira significativa ao seu conteúdo. A única exceção é o Cessar-Fogo, que foi oficialmente excluído das atribuições da missão nessa época, quando a ONU considerou que as atividades a ele relacionadas já tinham sido concluídas, ou poderiam ser assumidas pelo governo local ${ }^{15}$. A relação dos componentes da Unmil e sua ocorrência por ano, como aparece nos orçamentos anuais (2003-2008), estão resumidas no Quadro 1.

15 Cabe aqui uma ressalva relacionada ao Desarmamento, Desmobilização, Reabilitação e Reintegração Disarmament Demobilization Rehabilitation and Reintegration (DDRR): concluída a fase de desarmamento e desmobilização, em julho de 2005, as tarefas de reabilitação e reintegração foram transferidas para o componente Direitos Humanitários e Direitos Humanos (posteriormente chamado Primado da Lei), e o DDRR deixou de integrar o componente Cessar-Fogo. 
Quadro 1. Componentes da Unmil e ocorrência por ano (2003-2008).

\begin{tabular}{lcccccc}
\hline \multicolumn{1}{c}{ Componente } & 2003 & 2004 & 2005 & 2006 & 2007 & 2008 \\
\hline Cessar-Fogo & $\checkmark$ & $\checkmark$ & $\checkmark$ & $\checkmark$ & & \\
Direitos Humanitários e Direitos Humanos & $\checkmark$ & $\checkmark$ & $\checkmark$ & $\checkmark$ & $\checkmark$ & $\checkmark$ \\
Rule of Law & & & & & $\checkmark$ & $\checkmark$ \\
$\begin{array}{l}\text { Reforma do Setor de Segurança } \\
\text { Setor de Segurança }\end{array}$ & $\checkmark$ & $\checkmark$ & $\checkmark$ & $\checkmark$ & & \\
$\begin{array}{l}\text { Processo de Paz } \\
\text { Consolidação da Paz }\end{array}$ & $\checkmark$ & $\checkmark$ & $\checkmark$ & $\checkmark$ & & \\
Suporte & & & & & $\checkmark$ & $\checkmark$ \\
\hline
\end{tabular}

Adaptado de: A/58/539 2003; A/58/744 2004; A/59/630 2005; A/60/653 2006; A/61/783 2007; A/63/734 2008 (Orçamentos); A/59/736/Add.11 2004; A/60/852 2005; A/61/852/Add.7 2006; A/62/781/Add. 10 2007; A/63/746/Add.8 2008 (Relatórios de Desempenho Financeiro).

Tais componentes podem ser decompostos nos elementos apresentados a seguir, no Quadro 2.

Quadro 2. Componentes da Unmil e elementos a eles relacionados (2003-2008).

\begin{tabular}{|c|c|c|c|c|c|c|c|}
\hline Componente & Subcomponente & 2003 & 2004 & 2005 & 2006 & 2007 & 2008 \\
\hline \multirow[t]{3}{*}{ Cessar-Fogo } & $\begin{array}{l}\text { Manutenção da segurança e } \\
\text { do cessar-fogo }\end{array}$ & $\checkmark$ & $\checkmark$ & $\checkmark$ & $\checkmark$ & & \\
\hline & DDRR & $\checkmark$ & $\checkmark$ & & & & \\
\hline & $\begin{array}{l}\text { Formulação e implementação } \\
\text { de políticas }\end{array}$ & $\checkmark$ & $\checkmark$ & & & & \\
\hline \multirow{9}{*}{$\begin{array}{l}\text { Proteção } \\
\text { de Direitos } \\
\text { Humanitários } \\
\text { e Direitos } \\
\text { Humanos } \\
\text { (2003-2006); } \\
\text { Rule of Law } \\
\text { (2007-2008) }\end{array}$} & Monitoramento e pesquisa & $\checkmark$ & $\checkmark$ & $\checkmark$ & $\checkmark$ & $\checkmark$ & \\
\hline & DDRR & & & $\checkmark$ & $\checkmark$ & & \\
\hline & Retorno de refugiados e IDPs(1) & $\checkmark$ & $\checkmark$ & $\checkmark$ & $\checkmark$ & & \\
\hline & $\begin{array}{l}\text { Acesso das agências } \\
\text { humanitárias à população }\end{array}$ & $\checkmark$ & $\checkmark$ & $\checkmark$ & $\checkmark$ & & \\
\hline & Proteção dos DH & $\checkmark$ & $\checkmark$ & $\checkmark$ & $\checkmark$ & $\checkmark$ & \\
\hline & $\begin{array}{l}\text { Legal framework, policy } \\
\text { formulation, implementation }\end{array}$ & $\checkmark$ & $\checkmark$ & $\checkmark$ & $\checkmark$ & $\checkmark$ & \\
\hline & $\begin{array}{l}\text { Infraestrutura e serviços } \\
\text { básicos }\end{array}$ & & & $\checkmark$ & & & \\
\hline & Capacity building & $\checkmark$ & $\checkmark$ & $\checkmark$ & $\checkmark$ & $\checkmark$ & \\
\hline & $\begin{array}{l}\text { Investigação, justiça e } \\
\text { reconciliação }\end{array}$ & $\checkmark$ & $\checkmark$ & $\checkmark$ & $\checkmark$ & $\checkmark$ & \\
\hline
\end{tabular}




\begin{tabular}{|c|c|c|c|c|c|c|c|}
\hline Componente & Subcomponente & 2003 & 2004 & 2005 & 2006 & 2007 & 2008 \\
\hline \multirow{7}{*}{$\begin{array}{l}\text { Reforma } \\
\text { do setor de } \\
\text { segurança } \\
\text { (2003-2006); } \\
\text { Setor de } \\
\text { Segurança } \\
\text { (2007-2008) }\end{array}$} & Reestruturação da polícia & $\checkmark$ & $\checkmark$ & $\checkmark$ & $\checkmark$ & $\checkmark$ & \\
\hline & Reestruturação do exército & $\checkmark$ & $\checkmark$ & $\checkmark$ & $\checkmark$ & $\checkmark$ & \\
\hline & $\begin{array}{l}\text { Manutenção da segurança e } \\
\text { da ordem }\end{array}$ & $\checkmark$ & $\checkmark$ & $\checkmark$ & $\checkmark$ & $\checkmark$ & \\
\hline & Monitoramento e pesquisa & $\checkmark$ & $\checkmark$ & $\checkmark$ & $\checkmark$ & $\checkmark$ & \\
\hline & Capacity building & $\checkmark$ & $\checkmark$ & $\checkmark$ & $\checkmark$ & $\checkmark$ & \\
\hline & $\begin{array}{l}\text { Reestruturação dos sistemas } \\
\text { legal e correcional }\end{array}$ & $\checkmark$ & $\checkmark$ & $\checkmark$ & $\checkmark$ & $\checkmark$ & \\
\hline & Infraestrutura & & $\checkmark$ & $\checkmark$ & & $\checkmark$ & \\
\hline \multirow{7}{*}{$\begin{array}{l}\text { Processo } \\
\text { de paz } \\
\text { (2003-2006); } \\
\text { Consolidação } \\
\text { da paz } \\
(2007-2008)\end{array}$} & $\begin{array}{l}\text { Legal framework, policy } \\
\text { formulation, implementation }\end{array}$ & $\checkmark$ & $\checkmark$ & $\checkmark$ & $\checkmark$ & $\checkmark$ & $\checkmark$ \\
\hline & Eleições & $\checkmark$ & $\checkmark$ & $\checkmark$ & & & \\
\hline & DDRR & & & & & $\checkmark$ & $\checkmark$ \\
\hline & Monitoramento e pesquisa & $\checkmark$ & & & & $\checkmark$ & $\checkmark$ \\
\hline & Capacity building & $\checkmark$ & $\checkmark$ & $\checkmark$ & $\checkmark$ & $\checkmark$ & $\checkmark$ \\
\hline & Infraestrutura & $\checkmark$ & $\checkmark$ & $\checkmark$ & & & \\
\hline & Retorno de refugiados e IDPs & & & & & $\checkmark$ & $\checkmark$ \\
\hline
\end{tabular}

(1) Sigla em inglês que significa Internally Displaced People - deslocados ou refugiados internos. Adaptado de: A/58/539 2003; A/58/744 2004; A/59/630 2005; A/60/653 2006; A/61/783 2007; A/63/734 2008 (Orçamentos); A/59/736/Add. 11 2004; A/60/852 2005; A/61/852/Add.7 2006; A/62/781/Add.10 2007; A/63/746/Add.8 2008 (Relatórios de Desempenho Financeiro).

Nesse sentido, observa-se que os elementos relacionados aos componentes Cessar-Fogo e Reforma do Setor de Segurança são condizentes com o objetivo de devolver ao Estado a capacidade de manter a segurança internamente e o monopólio sobre os meios de violência, além de possibilitarem a reconstituição da sociedade civil, especialmente após os processos de desmobilização e desarmamento ${ }^{16}$. No componente Processo de Paz, os elementos de reconstrução institucional e da estrutura administrativa fazem parte dos esforços para reerguer as bases do Estado soberano para que ele possa, progressivamente, recuperar sua independência em relação aos principais Estados e atores internacionais e, domesticamente, estender autoridade por todo o território sob sua jurisdição. Além disso, com a inclusão das eleições entre os elementos do processo de paz, percebe-se que a independência desse Estado que será recriado como sujeito da sociedade internacional não inclui a prerrogativa de definir a forma de organizar as relações políticas internamente. Nesse quesito, a democracia se impóe como modelo universal e único caminho possível para levar à paz.

16 É importante perceber que tal perspectiva é em grande medida tributária das experiências europeias e da OTAN, particularmente no que se refere à reforma do setor de segurança. Agradecemos ao parecerista anônimo da RBPI por essa sugestão. A esse respeito, veja-se também Albrecht, Stepputat e Andersen (2010). 
A inclusão dos elementos de proteção e promoção dos direitos fundamentais e liberdades individuais revela a importância atribuída à definição de marcos legais e jurídicos, característicos das democracias liberais. A permanência de elementos relacionados à proteção humanitária ao longo dos anos de intervenção, além de viabilizar o controle de uma situação de emergência, procura garantir a melhoria de condições básicas de vida, como educação, saúde e padrões apropriados de nutrição. O componente conta ainda com o elemento de reabilitação e reintegração, relacionado à educação de ofícios a ex-combatentes e grupos afetados pela violência em troca de alimentos ou remuneração; e, posteriormente, da criação de empregos e financiamento das atividades produtivas por eles desenvolvidas.

Tomando por base os componentes e elementos ${ }^{17}$ constitutivos da missão, percebe-se que o processo de reconstrução empreendido pela Unmil na Libéria não visa à edificação de um Estado qualquer, e, sim, de um Estado liberal democrático, com mercado interno livre e sólido e administração pública pautada por padrões de boa governança, estabelecidos pelas agências internacionais; em uma palavra: um Estado normal. A normalização é resultado da combinação de práticas de segurança e desenvolvimento, sustentada por uma perspectiva que entende a paz não como resultado da estabilização, mas como um processo de promoção da segurança humana ${ }^{18}$. Uma vez normalizado, tal Estado seria capaz de garantir as condiçôes necessárias à paz duradoura e atuar como membro pleno do sistema internacional, participando ativamente de suas principais instituições.

\section{Considerações finais: segurança, desenvolvimento e normalização do sistema internacional}

Tomadas em conjunto, as transformações normativas, institucionais e operacionais que tiveram lugar a partir dos anos 1990 podem ser entendidas como parte do processo de emergência de um novo conjunto de práticas de manutenção da paz conduzidas pela ONU. Entre suas características, deve-se destacar a multidimensionalidade e a participação de novos atores, que evidenciam o envolvimento mais consistente da sociedade internacional nos processos de pacificação e reconstrução de Estados nacionais. Contudo, é interessante observar que, apesar da cadência e coerência aparentes entre propostas e decisóes, a reconstituição dessas operações como instrumentos de manutenção da paz e da segurança internacional foi muitas vezes marcada pela descontinuidade.

17 Como o componente Suporte e os elementos a ele relacionados dizem respeito à organização da missão e não ao processo de reconstrução propriamente dito, o mesmo foi desconsiderado.

18 Uma vez que a paz deixa de ser entendida como estabilização para ser tratada como segurança humana que tem como suporte o indivíduo e as condiçōes necessárias à sua existência digna, alguns autores sugerem que, em lugar de se tratar de um processo de securitização do desenvolvimento, estaríamos diante da "desenvolvimentalização" (developmentalization) do desenvolvimento. A esse respeito veja-se Stepputat (2007) e Albrecht, Stepputat e Andersen (2010). 
Grande parte das inovaçóes hoje sistematizadas em documentos como a Doutrina Capstone (2008) resultou, de fato, da compilação de experiências ad hoc, relativas a necessidades impostas por circunstâncias particulares que cercaram cada um dos casos nos quais a ONU se envolveu.

Outra questão digna de nota diz respeito ao fato de que, sob a égide da multidimensionalidade, as operações tornaram-se mais dispendiosas, tanto política quanto economicamente, e seu sucesso, traduzido aqui como realização efetiva dos projetos e programas tidos como essenciais, progressivamente condicionado ao suporte oferecido pelos Estados. Dessa forma, a aplicação de novos conceitos, padrōes e técnicas dependeu não só de seu desenvolvimento e disponibilidade, como também do apoio internacional recebido em cada caso. Ao longo dos anos, as operaçōes capazes de combinar inovaçōes e recursos de forma bem-sucedida foram utilizadas pela ONU na definição de um rol de práticas testadas e aceitas (melhores práticas) que informariam experiências subsequentes.

A operação realizada na Libéria a partir de 2003 pode ser incluída nesse grupo, uma vez que, como pudemos observar, além de reunir princípios e técnicas desenvolvidos até então, teve êxito em criar novas soluções e incorporar, ao longo de sua atuação, práticas que se mostraram eficientes em outros casos. Dessa forma, a missão foi considerada pela ONU representante exemplar da nova geração das operações de paz, tornando-se referência para futuras intervenções e inspiração para documentos como a Doutrina Capstone (2008).

Este artigo teve como ponto de partida a hipótese de que após a Guerra Fria seria possível identificar a emergência de um entendimento intersubjetivo que identificava a paz com a difusão do modelo liberal democrático de organização político-social (tratado aqui como processo de normalização). O estudo do caso da Unmil nos permitiu descrever a montagem e o funcionamento de uma OMP, que carregou consigo o ímpeto normalizador apontado na hipótese de trabalho. De fato, nos foi possível identificar evidências das orientações normativas, institucionais e operacionais que informam os processos de pacificação e reconstrução de Estados após a Guerra Fria tanto em seu mandato quanto nos itens de dispêndio que compuseram seus orçamentos.

Apesar de as áreas de segurança e assistência ao desenvolvimento terem, tradicionalmente, caráter bastante distinto, o objetivo de manter a paz parece ser comum a ambas. Além disso, a análise dos elementos que cada uma elenca entre os caminhos para que seu projeto se perpetue permite identificar a emergência de uma acepção de paz diferente da "ausência de conflito armado". Mais do que preservar a capacidade dos Estados soberanos de governar sua população de forma independente e de fazê-lo amparado pelo monopólio dos meios de violência dentro do território sob sua jurisdição, o conceito de paz que emergiu, discursivamente, no final do século 20 e início do 21, parece ter tido sucesso em incluir nessa lista aspectos que dizem respeito ao modo de governar e organizar as relações sociais. 
Essa inclusão, ao que tudo indica, pautou-se na consolidação de uma versão do pensamento liberal que afirma a existência de um rol de direitos universais e a relação direta entre a preservação desses direitos e a manutenção da paz (Doyle 1996; Owen 1996). Pela reivindicação de universalidade, seus partidários se julgam capazes de fornecer modelos que poderiam ser aplicados em qualquer país, de modo que a paz e o desenvolvimento fossem difundidos e fortalecidos em todo o mundo. Entretanto, a suposta universalidade dos modelos tem ainda outras implicações para as OMP, nomeadamente, a comunhão de objetivos e propostas entre os agentes da reconstrução; e a inclusão de novos atores, como ONGs e empresas privadas. Uma vez que os objetivos são reescritos como universais, as agendas de segurança e de desenvolvimento tornam-se progressivamente convergentes, o que se revela na aproximação entre as políticas circunscritas a cada uma delas. Tal aproximação permite indagar a própria natureza dos processos de pacificação em curso no sistema internacional. Nesse sentido, é possível afirmar que após a Guerra Fria, democracia, segurança e desenvolvimento são amalgamadas em um único cadinho, vale dizer, em um único conjunto de técnicas de exercício de poder, nomeadas governança global. Nesse caso, podemos considerar que as técnicas de governança global transformaram a paz democrática em uma estratégia de governo do próprio sistema internacional (Zanotti 2005), transformando-o em um espaço normalizado ou, se preferirmos, em processo de normalização. Nesse processo, as operações de manutenção da paz aparecem como técnicas de governo que seriam desdobradas para guiar, formar e fazer avançar tipos específicos de Estados, por meio do estabelecimento de padrões de comportamento individual e modelos institucionais que devem ser implementados e seguidos por todos os bons membros da comunidade internacional.

\section{Referências bibliográficas}

ALBRECHT, Peter, Finn Stepputat, and Louise Andersen. 2010. Security Sector Reform: the European way. In The Future of Security Sector Reform, edited by M. Sedra. Waterloo: The Centre for International Governance Innovation.

ADEBAJO, Adekeye. (2002) Liberia’s Civil War: Nigeria, ECOMOG and Regional Security in West Africa. London: Lynne Reinner Publishers.

ANING, Emmanuel K. (1999) Security in the West African Subregion: an Analysis of ECOWAS' Policies in Liberia. Copenhagen: Institute of Political Science, University of Copenhagen.

BELLAMY, Alex J., and Paul Williams. 2004. Introduction: Thinking anew about peace operations. International Peacekeeping 11 (1):1-15.

BUCHANAN, Allen, and Robert O. Keohane. 2004. The Preventive Use of Force: a Cosmopolitan Institutional Proposal. Ethics and International Affairs 18 (1):1-22.

CARNEGIE COMMISSION ON PREVENTING DEADLY CONFLICT (1997) Preventing Deadly Conflict Final Report, publicado em [http://www.wilsoncenter.org/subsites/ccpdc/pubs/ rept97/finfr.htm]. Disponibilidade: 28 de outubro de 2008. 
CHANDLER, David. (2007) The security-development nexus and the rise of 'anti-foreign policy'. Journal of International Relations and Development, Vol.10, 2007, p.362-386.

CHANDLER, David. 2002. From Kosovo to Kabul and beyond: human rights and international intervention. London: Pluto Press.

CHANDLER, David. 2004. The Responsibility to Protect? Imposing the 'Liberal Peace'. International Peacekeeping 11 (1):59-81.

CLAUDE, Inis L. (1956) Swords into plowshares; the problems and progress of international organization. New York: Random House.

CGG. (1996) Nossa Comunidade Global. Rio de Janeiro: Ed. Fundação Getúlio Vargas.

CSH. (2003) Human Security Now, publicado em [http://www.humansecurity-chs.org/ finalreport/English/FinalReport.pdf]. Disponibilidade: 10 de julho de 2009.

DAVID, M. S. (1984) The Love of Liberty Brought Us Here: An Analysis of the Development of the Settler State in Nineteenth Century Liberia 1984. Review of African Political Economy, No 31, 1984.

DEBRIX, François. 1999. Re-envisioning peacekeeping: the United Nations and the mobilization of ideology, Borderlines. Minneapolis: University of Minnesota Press.

DOYLE, Michael. 1996. Kant, liberal legacies and foreign affairs. In Debating the democratic peace, edited by M. E. Brown, S. M. Lynn-Jones and S. E. Miller. Cambridge, Mass.: MIT Press.

DOYLE, Michael W., and Stephen Macedo. 2008. Striking first: preemption and prevention in international conflict, The University Center for Human Values series. Princeton, NJ: Princeton University Press.

DOYLE, Michael W., and Nicholas Sambanis. 2006. Making war and building peace: United Nations peace operations, Princeton paperbacks. Princeton, N.J.: Princeton University Press.

DPKO (2007). Fact Sheet, publicado em [http://www.un.org/Depts/dpko/dpko/info/page3. htm]. Disponibilidade: 7 de setembro de 2008.

DPKO/DFS (2008). Capstone Doctrine, publicado em [http://pbpu.unlb.org/pbps/Library/ Capstone_Doctrine_ENG.pdf]. Disponibilidade: 13 de maio de 2009.

DOBBINS, James et al. (2007) The Beginners Guide to Nation-Building. New York: Rand Corporation.

DUFFIELD, Mark R. 1994. Complex emergencies and the crisis of developmentalism. IDS Bulletin: Linking Relief and Development, 25 (3).

DUFFIELD, Mark R. 2001. Global governance and the new wars: the merging of development and security. London: Zed Books.

DURCH, William, Victoria K. Holt, Caroline R. Earle, and Moira K. Shanahan. 2003. The Brahimi Report and the Future of UN Peace Operations. Nova York: The Henry L. Stimson Center

DURCH, William. 1993. The Evolution of UN peacekeeping: case studies and comparative analysis. New York, NY: St. Martin's Press.

DURCH, William. 2006. Twenty-first-century peace operations. Washington, D.C.: United States Institute of Peace and the Henry L. Stimson Center.

ESTEVES, Paulo; SOUZA, Letícia Carvalho. (2008). Pax Perpetua: o internacional e a modernidade tardia. Cena Internacional, Vol. 10, No 1, 2008, p. 63-97. 
ESTEVES, Paulo. 2010A. Peace Operations and the Government of Humanitarian Spaces. International Peacekeeping 17:613-628.

ESTEVES, Paulo. 2010B. A Convergência entre Práticas Humanitárias e Segurança Internacional. Belo Horizonte: Del Rey.

GADDIS, John L. (2005) The Cold War: a new history. New York: Penguin Press.

HARRIS, David. (1999) From 'warlord' to 'democratic' president: how Charles Taylor won the 1997 Liberian elections. The Journal of Modern African Studies. Vol. 37, No. 3, 1999.

HOFFMAN, Daniel. (2006) Despot deposed: Charles Taylor and the challenge of state reconstruction Liberia. In: SOUTHALL, Roger; MELBER, Herring. Ed. (2006) Legacies of Power: Leadership Change and Former Presidents in African Politics. Chicago: Independent Publishers Group.

HOWE, Herbert M.(2001) Ambiguous Order: Military Forces in African States. London: Lynne Reinner Publishers.

INTERNATIONAL CRISIS GROUP (2003). Liberia: Security Challenges. ICG Africa Report No 71, publicado em [http://www.crisisgroup.org/home/index.cfm?id=1237]. Disponibilidade: 18 de setembro de 2009.

LEDERACH, J. P. 2002. Into The Eye Of The Storm: A Handbook Of International Peacebuilding. San Francisco: Jossey-Bass.

LEDERACH, J. P. 2003. Cultivating Peace: A Practitioner's View of Deadly Conflict and Negotiation. In Contemporary Peacemaking: Conflict, Violence and Peace Processes, edited by J. Darby and R. MacGinty. New York: Palgrave MacMillan.

LEVITT, Jeremy I. (2005) The Evolution of Deadly Conflict in Liberia. North Carolina: Carolina Academic Press.

LEWIS, William H, and Thomas Julian. 1992. Military implications of United Nations peacekeeping operations. Washington: National Defense University.

MORGAN, E. P. (2006) Liberia and the Fate of Interim Government in the Regional Vortex of West Africa. Strategic Insights, Vol. 5, No 1, 2006.

NDUMBE, A; BABALOLA, C.(2005) The Illicit Diamond Trade. Civil Conflicts. and Terrorism in Africa. Mediterranean Quarterly. Vol. 60, No. 2, 2005.

NELSON, H.D. (1984) Liberia: A Country Profile. Washington, D.C.: US Government Printing Office.

ONU. Assembléia Geral (2003). A/58/539. Budget for the United Nations Mission in Liberia (1 August 2003 to 30 June 2004), publicado em [http://documents-dds-ny.un.org/doc/UNDOC/ GEN/N03/587/24/pdf/N0358724.pdf?OpenElement]. Disponibilidade: 12 de agosto de 2008.

ONU. (2004). A/58/744. Budget for the United Nations Mission in Liberia (1 July 2004 to 30 June 2005), publicado em [http://documents-dds-ny.un.org/doc/UNDOC/GEN/N04/279/76/ img/N0427976.pdf?OpenElement]. Disponibilidade: 12 de agosto de 2008.

ONU. (2005) A/59/630. Budget for the United Nations Mission in Liberia (1 July 2005 to 30 June 2006), publicado em [http://documents-dds-ny.un.org/doc/UNDOC/GEN/N04/658/83/ pdf/N0465883.pdf?OpenElement]. Disponibilidade: 12 de agosto de 2008.

ONU. (2005). A/59/736/Add.11: Financial performance report (1 August 2003 to 30 June 2004) and proposed budget (1 July 2005 to 30 June 2006) of the United Nations Mission in Liberia, publicado em [http://documents-dds-ny.un.org/doc/UNDOC/GEN/N05/311/90/ pdf/N0531190.pdf?OpenElement]. Disponibilidade: 3 de janeiro de 2009. 
ONU. (2006) A/60/653. Budget for the United Nations Mission in Liberia (1 July 2006 to 30 June 2007), publicado em [http://documents-dds-ny.un.org/doc/UNDOC/GEN/N06/215/07/ pdf/N0621507.pdf?OpenElement]. Disponibilidade: 12 de agosto de 2008.

ONU. (2007). A/61/783. Budget for the United Nations Mission in Liberia (1 July 2007 to 30 June 2008), publicado em [http://documents-dds-ny.un.org/doc/UNDOC/GEN/N07/260/84/ pdf/N0726084.pdf?OpenElement]. Disponibilidade: 12 de agosto de 2008.

ONU. (2006) A/61/852/Add.7: Financial performance report (1 July 2004 to 30 June 2005) and proposed budget (1 July 2006 to 30 June 2007) of the United Nations Mission in Liberia, publicado em [http://documents-dds-ny.un.org/doc/UNDOC/GEN/N06/351/47/pdf/ N0635147.pdf?OpenElement]. Disponibilidade: 3 de janeiro de 2009.

ONU. (2007) A/62/781/Add.10: Financial performance report (1 July 2005 to 30 June 2006) and proposed budget (1 July 2007 to 30 June 2008) of the United Nations Mission in Liberia, publicado em [http://documents-dds-ny.un.org/doc/UNDOC/GEN/N07/311/84/ pdf/N0731184.pdf?OpenElement]. Disponibilidade: 3 de janeiro de 2009.

ONU. (2008). A/63/734. Budget for the United Nations Mission in Liberia (1 July 2008 to 30 June 2009), publicado em [http://documents-dds-ny.un.org/doc/UNDOC/GEN/N07/260/84/ pdf/N0726084.pdf?OpenElement]. Disponibilidade: 3 de janeiro de 2009.

ONU. (2008). A/63/746/Add.8: Financial performance report (1 July 2006 to 30 June 2007) and proposed budget (1 July 2008 to 30 June 2009) of the United Nations Mission in Liberia, publicado em [http://documents-dds-ny.un.org/doc/UNDOC/GEN/N08/343/49/pdf/ N0834349.pdf?OpenElement]. Disponibilidade: 3 de janeiro de 2009.

ONU. Conselho de Segurança. An Agenda for Peace, publicado em [http://www.un.org/docs/ SG/agpeace.html]. Disponibilidade: 15 de fevereiro de 2008.

ONU. Conselho de Segurança. (2003). S/2003/769: Report of the Secretary-General to the Security Council on Liberia, publicado em [http://daccessdds.un.org/doc/UNDOC/GEN/ N03/445/30/PDF/N0344530.pdf?OpenElement]. Disponibilidade: 12 de agosto de 2008.

ONU. Conselho de Segurança. (2003) S/2003/875: Report of the Secretary-General to the Security Council on Liberia, publicado em [http://daccessdds.un.org/doc/UNDOC/GEN/ N03/491/10/PDF/N0349110.pdf?OpenElement]. Disponibilidade: 12 de agosto de 2008.

ONU. Conselho de Segurança.(1995). S/RES/1020: Resolution, publicado em [http:// daccessdds.un.org/doc/UNDOC/GEN/N95/348/93/PDF/N9534893.pdf?OpenElement]. Disponibilidade: 12 de agosto de 2008.

ONU. Conselho de Segurança. (2003). S/RES/1497: Resolution, publicado em [http:// daccessdds.un.org/doc/UNDOC/GEN/N03/449/48/PDF/N0344948.pdf?OpenElement]. Disponibilidade: 12 de agosto de 2008.

ONU. Conselho de Segurança. (2003). S/RES/1509: Resolution, publicado em [http:// daccessdds.un.org/doc/UNDOC/GEN/N96/137/26/PDF/N9613726.pdf?OpenElement]. Disponibilidade: 12 de agosto de 2008.

ONU. Conselho de Segurança. (2009). S/RES/1855: Resolution, publicado em [http://unmil. org/documents/resolutions/SCR\%201885\%20(2009).pdf]. Disponibilidade: 3 de janeiro de 2010 .

ONU. Conselho de Segurança. (1992). S/RES/788: Resolution, publicado em [http:// daccessdds.un.org/doc/UNDOC/GEN/N93/010/46/IMG/N9301046.pdf?OpenElement]. Disponibilidade: 12 de agosto de 2008. 
ONU. Conselho de Segurança. (1993). S/RES/866: Resolution, publicado em [http:// daccessdds.un.org/doc/UNDOC/GEN/N93/513/89/PDF/N9351389.pdf?OpenElement]. Disponibilidade: 12 de agosto de 2008.

ONU (2000). United Nations and Liberia, publicado em [http://www.un.org/peace/africa/ pdf/Liberia.pdf]. Disponibilidade: 19 de outubro de 2009.

OWEN, John M. 1996. How liberalism produces democratic peace. In Debating the democratic peace, edited by M. E. Brown, S. M. Lynn-Jones and S. E. Miller. Cambridge, Mass.: MIT Press.

PARIS, Roland. 2001. Echoes of the Mission Civilizatrice: peacekeeping in the post-cold war era. In United Nations and Human Security, edited by E. Newman. Gordonsville: Palgrave.

PARIS, Roland. (2007) Post-conflict Peacebuilding. In: WEISS, T; DAWS, S. Ed. (2007) The Oxford Handbook on the United Nations. New York: Oxford University Press, p.404-426.

PNUD (1994). Human Development Report. New York: Oxford University Press.

PUGH, Michael. 2004. Peacekeeping and Critical theory. International Peacekeeping 11 (1):39-58.

PURVIS, T. (1997) Dictionary of American History. Cambridge, Mass.: Blackwell Publishing. REUS-SMIT, Christian. 2005. Liberal hierarchy and the licence to use force. Review of International Studies 31:21.

RICHMOND, Oliver P. 2005. The transformation of peace, Rethinking peace and conflict studies. Basingstoke [England]; New York: Palgrave Macmillan.

RICHMOND, Oliver P. 2010. Resistance and the Post-liberal Peace. Millennium - Journal of International Studies (38):665-692.

RICHMOND, Oliver P., and Jason Franks. 2009. Liberal peace transitions: between statebuilding and peacebuilding. Edinburgh: Edinburgh University Press.

RUSSETT, Bruce, and Zeev Maoz. 1993. Normative and Structural Causes of Democratic Peace, 1946-1986. The American Political Science Review 87 (3):624-638.

SAWYER, Amos. (2004) Violent conflicts and governance challenges in West Africa: the case of the Mano River Basin Area. Journal of Modern African Studies, Vol. 32, No. 3, 2004, p. 434-444.

SAYLE, T et al. (2009) Liberia: Assessing the Conditions for Liberal Democracy in a Postconflict State. Creating an International Network of Democracy Builders, Vol. 2, publicado em [http:// www.queensu.ca/csd/documents/09.02.02_Liberia_000.pdf]. Disponibilidade: 19 de outubro de 2009.

STEPPUTAT, Finn. 2007. The security-development Nexus. Expressions of Sovereignty and Securitization in Southern Africa. Uppsala and Cape Town: Nordic Africa Institute and HCRC Press.

UN FORUM. (2005) Liberia: a UN Success Story, publicado em [http://www.unforum.com/ UNheadlines288.htm]. Disponibilidade: 1 de setembro de 2009.

UN FOUNDATION. (2009) UN Peacekeeping is a Success in Liberia, publicado em [http://www.unfoundation.org/our-impact/stronger-un/supporting-un-peacekeeping.html]. Disponibilidade: 1 de setembro de 2009.

UNDAF. (2003) Liberia: a modified UNDAF (2003-2005), publicado em [http://www.undg. org/unct.cfm?CountryID=LIR\&fuseaction=UN\%20Country\%20Coordination $\% 20$ Profile \& module $=$ CoordinationProfile $\&$ page $=$ Country]. Disponibilidade: 12 de agosto de 2008 . 
UNDAF. (2008) Liberia: Consolidating Peace and National Recovery for Sustainable Development (2008-2012), publicado em [http://unliberia.org/doc/undaf_doc.pdf]. Disponibilidade: 18 de junho de 2009.

WICKSTROM, W. (1960) The American Colonization Society and Liberia, 1817-1867. Monróvia: College of West Africa.

ZANOTTI, Laura. (2005) Governmentalizing the post-cold war international regime: the UN debate on democratization and good governance. Alternatives: Global, Local, Political, Vol. 30, No. 4, 2005.

Recebido em 7 de setembro de 2010 Aprovado em 6 de junho de 2011

\title{
Resumo
}

O artigo trata das transformações sofridas pelas OMP conduzidas pela ONU no pós-Guerra Fria. A partir do caso liberiano, pretende-se mostrar a consolidação de um nexo entre segurança e desenvolvimento, o qual relacionar-se-ia a um processo mais amplo de normalização das relações internacionais, informado por um vocabulário liberal-democrático.

Palavras-chave: desenvolvimento; Libéria; segurança.

\begin{abstract}
The paper addresses the transformation of UN peacekeeping operations after the Cold War, based on the Liberian case. The aim is to show the consolidation of a nexus between security and development, which would be related to a process of normalization of international relations, informed by a liberal-democratic vocabulary.
\end{abstract}

Keywords: development; Liberia; security. 